\title{
New Paradigms for Colonoscopic Management of Diminutive Colorectal Polyps: Predict, Resect, and Discard or Do Not Resect?
}

\author{
Cesare Hassan', Alessandro Repici', Angelo Zullo and Prateek Sharma ${ }^{2}$ \\ ${ }^{1}$ Digestive Endoscopy Unit, Istituto Clinico Humanitas, Milan, Italy, ${ }^{2}$ Division of Gastroenterology, University of Kansas Medical Center, Kansas City, \\ KS, USA
}

\begin{abstract}
The possibility to predict in vivo the histology of colorectal polyps by advanced endoscopic imaging has resulted in the implementation of a more conservative management for diminutive lesions detected at colonoscopy. In detail, a predict-and-do-not-resect strategy has been proposed for diminutive lesions located in the rectosigmoid tract, whilst a predict-resect-and-discard policy has been advocated for nonrectosigmoid diminutive polyps. Recently, the American Society for Gastrointestinal Endoscopy set required thresholds to be met, before allowing the adoption of these policies in the clinical field. The ability of current endoscopic imaging in reaching these thresholds would depend on a complex interaction among the accuracy of advanced endoscopic imaging in differentiating between adenomatous and hyperplastic lesions, the prevalence of (advanced) neoplasia within diminutive lesions, and the type of surveillance intervals recommended. Aim of this review is to summarize the data supporting the application of both a predict-and-do-not-resect and a predict-resect-and-discard policies, also addressing the potential pitfalls associated with these strategies.
\end{abstract}

Key Words: Electronic chromoendoscopy; Colonoscopy; Polypectomy; Narrow band imaging; Preservation and incorporation of valuable endoscopic innovation

\section{INTRODUCTION}

Any decision-making process in clinical medicine may be simplified in a series of sequential steps that cumulatively lead to a clinical diagnosis or intervention. Thus, the additional benefit of any step must be balanced with the associated exploitation of medical and economic resources. When limiting our focus to diagnostic process, the additional value of any subsequent test will depend on the absolute increase in accuracy as compared with what was achieved prior to the test.

Histological examination of colorectal lesions has been considered in the last decades as a critical step in the decisionmaking process, because of its contribution in differentiating between nonneoplastic and neoplastic lesions, and - among

Received: January 28, 2013 Revised: February 13, 2013

Accepted: February 13, 2013

Correspondence: Cesare Hassan

Division of Gastroenterology, Ospedale Nuovo Regina Margherita Hospital, Via E. Morosini 30, I-00153 Rome, Italy

Tel: +39-3387922296, Fax: +39-3387922296, E-mail: cesareh@hotmail.com

(c) This is an Open Access article distributed under the terms of the Creative Commons Attribution Non-Commercial License (http://creativecommons.org/ licenses/by-nc/3.0) which permits unrestricted non-commercial use, distribution, and reproduction in any medium, provided the original work is properly cited. those neoplastic - between noninvasive and invasive lesions. ${ }^{1,2}$ The relevance of postpolypectomy histological examination has been intimately related with the lack of any alternative in characterizing polypoid or nonpolypoid lesions prior to the pathological examination itself. ${ }^{1,2}$ Despite histological characterization of colorectal polyps has been generally considered as a gold-standard, some pitfalls may be identified. First, not all the removed polyps are actually retrieved, resulting into a complete loss of information in $10 \%$ to $20 \%$ of cases. ${ }^{3} \mathrm{Sec}-$ ondly, a high interobserver variability in the diagnosis of the degree of dysplasia and villous component - i.e., the unfavourable features discriminating between advanced and nonadvanced neoplasia - has been shown. ${ }^{4}$ Third, the same differentiation between hyperplastic and adenomatous histotypes is not perfect, with adenomatous tissue hidden in the nonexamined part of the embedded specimen. Fourth, there is no general consensus on the clinical meaning of histological characterization with divergent recommendations according to different guidelines. ${ }^{5,6}$

The need of postpolypectomy histological examination causes a substantial exploitation of medical and economic resources. It may be estimated that roughly one in every two 
patients undergoing screening or diagnostic colonoscopy are diagnosed with at least one polyp, thus requiring postpolypectomy pathological examination. ${ }^{7.8}$ Secondly, the vast majority of these polyps are diminutive ( $\leq 5 \mathrm{~mm}$ ) with a very low prevalence of advanced neoplasia, marginalizing the clinical impact of pathological examination.-9 ${ }^{7-9}$ hird, the estimated cost of the pathological examination is of the same magnitude with that of colonoscopy, heavily affecting the cost of colonoscopy screening without adding an equivalent contribution to colonoscopy efficacy. ${ }^{10-12}$ Fourth, the need of a new visit for communicating the postpathological surveillance interval generates a substantial and avoidable loss of productivity for the society, especially when considering that roughly $60 \%$ of the United States population undertakes a screening colonoscopy every 10 years. ${ }^{13}$

In order to address these pitfalls, a policy of discarding the postpolypectomy pathological examination has been proposed, also named as predict-resect-and-discard policy. ${ }^{14-16}$ Its main assumption is that if endoscopy may predict in vivo the histotype of the polyp, the additional value of histological examination may be marginalized, becoming inefficient and/or cost-ineffective. ${ }^{10-12}$ Predict-resect-and-discard policy has been mainly prompted by the technical evolution of endoscopic imaging, leading to a new field defined as advanced endoscopic imaging, with the main aim of differentiating between hyperplastic and neoplastic, as well as between noninvasive and invasive neoplastic lesions. ${ }^{1718}$ However, before implementing a predict-resect-and-discard policies, several issues need to be addressed. First, in vivo prediction of polyp histology is required to reach an adequate level of accuracy, in order to minimize the possible contribution of postpolypectomy histological examination to the decision-making process. Secondly, a high degree of inter and intraobserver agreement is required, in order to assure its reproducibility. Third, a feasible training and learning curve must be in place, in order to result into an adequate generalizability of the predictresect-and-discard strategy. Fourth, advanced imaging techniques need to be supported by the available endoscopic systems. Fifth, the appropriateness of the clinical recommendations - i.e., the postpolypectomy surveillance intervals - should not be deteriorated by the exclusion of pathological examination. Sixth, a standardized and formal reporting of in vivo histological prediction must be in place, in order to prevent misuse or eventual medical litigations related with the implementation of this policy.

Aim of this review is to address the pros and cons of a predict-resect-and-discard policy based on the data available in the literature.

\section{ADVANCED ENDOSCOPIC IMAGING}

Standard white light endoscopy has been regarded as inaccurate to accurately predict in vivo the histological features of colorectal lesions. Sensitivity has been shown to broadly range between $60 \%$ and $90 \%$, with specificity ranging between $40 \%$ and $90 \% .{ }^{19-21}$ The evolution from standard to high-definition endoscopy disappointingly failed to meaningfully improve the suboptimal white light accuracy in characterizing colorectal polyps. ${ }^{19}$ The possibility to in vivo differentiate among different histotypes has been initially shown by Japanese endoscopists. ${ }^{2,17,18,22,23}$ Briefly, it was exploited the ability of some dyes - such as indigo carmine and methylene blue - to highlight the pit pattern of colorectal lesions at high-(optical) magnification endoscopy. ${ }^{2,17,18,22,23}$ The pit pattern of both polypoid and nonpolypoid lesions was shown to be intimately associated with the progressive distortion and elongation of colonic glands during colorectal cancer (CRC) carcinogenesis or, alternatively, with the evolution towards a serrated - mainly hyperplastic - histotypes. ${ }^{217,18,22,23}$ However, dye-chromoendoscopy failed to be successfully implemented in Western countries for several reasons. First, Japanese endoscopists appeared to be more prone to implement chromoendoscopy in colonoscopy, because chromoendoscopy had already been routinely adopted for population-based gastric cancer screening. ${ }^{24} \mathrm{Sec}-$ ondly, dye spraying has been generally discarded as time-consuming and inconvenient, also when considering the intensive volume of screening colonoscopies performed in Western countries. ${ }^{13}$ Thirdly, dye-chromoendoscopy requires a long-lasting learning curve, possibly including several hundreds of examinations. ${ }^{2,16,17,21,22}$ Fourth, chromoendoscopy has been primarily exploited for differentiating between endoscopically and surgically resectable submucosal cancer in nonpolypoid lesions rather than for discriminating between nonneoplastic and neoplastic lesions. ${ }^{2,16,17,21,22}$ Fifth, an excessive dye spraying may substantially reduce the visibility of the mucosa surrounding the targeted lesion, potentially affecting the detection rate of more serious lesions.

For all these reasons, there was the need of a major breakthrough to expand the success of advanced endoscopic imaging to Western countries. As detailed by Rastogi et al. in this issue of Clinical Endoscopy, the advent of electronic chromoendoscopy (EC) - such as narrow band imaging, Fuji intelligent color enhancement, and Pentax I-Scan - opened the door for the in vivo prediction of polyp histology in Western countries. First, EC has shown a promising accuracy in differentiating between adenomatous and hyperplastic polyps in several studies (Table 1), ${ }^{9,14-16,19-21,25-52}$ owing to the advantage of being extremely simple and fast to be activated. Secondly, the level of confidence of the operator in the in vivo prediction has 


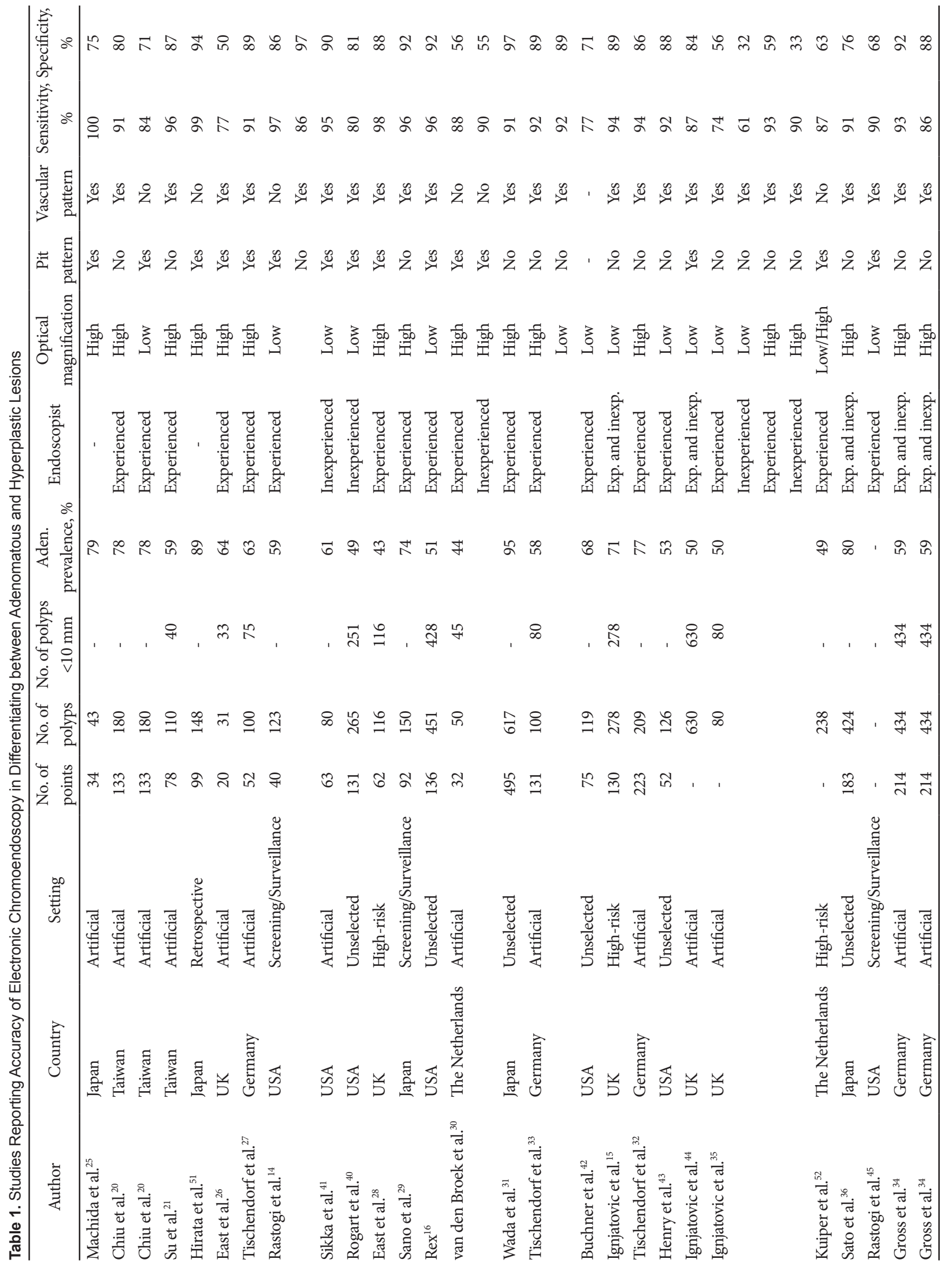




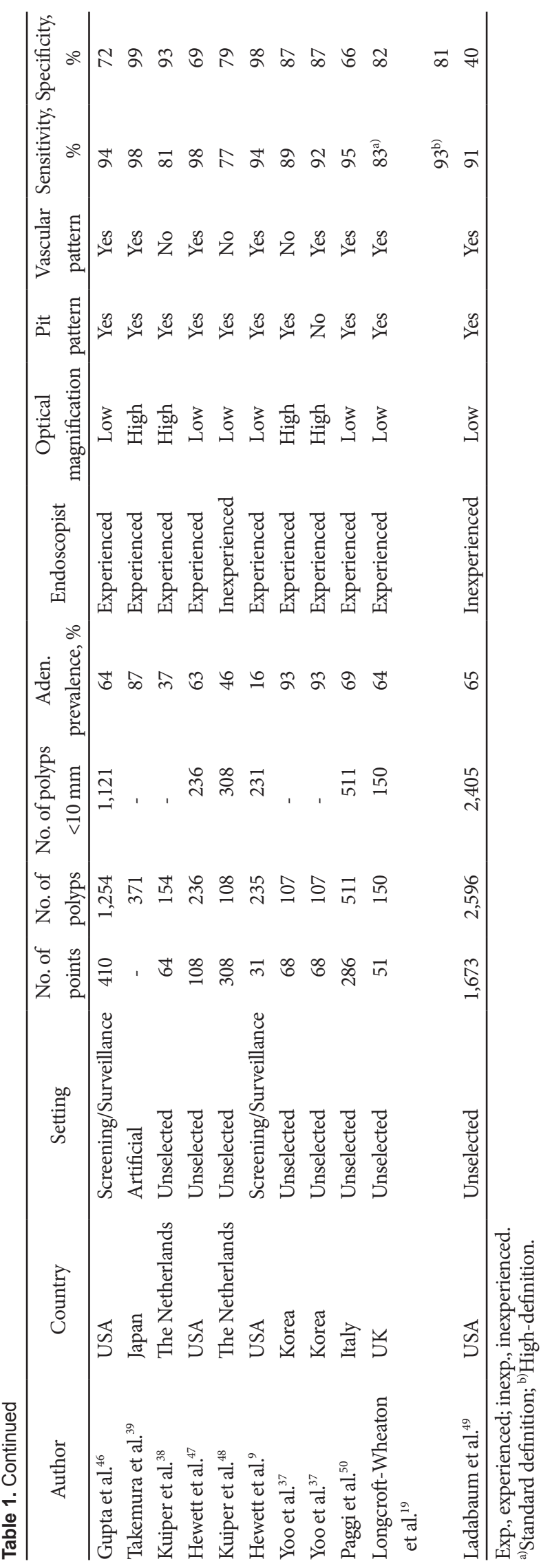

been associated with EC accuracy, so that - by restricting the analysis only to the high-confidence diagnosis - EC accuracy may be further improved. ${ }^{9,15,16,47-49}$ Third, EC is available on the new generation of endoscopes, so that a widespread implementation of this technique may be expected. Fourth, a very fast and simple training and learning curve has been shown to be feasible, also leading to acceptable rates of inter and intraobserver agreements, thus assuring the generalizability and reproducibility of the in vivo characterization..$^{25,47,53}$

\section{PREDICT-RESECT-AND-DISCARD AND PREDICT-AND-DO-NOT RESECT POLICIES}

The efficacy and safety of strategies based on in vivo characterization of colorectal lesions depends on a complex interaction between the accuracy values of EC, the expected prevalence of disease, and the types of surveillance intervals recommended. The main criticism to EC-based prediction is its inability in discriminating between nonadvanced and advanced neoplasia. ${ }^{911-16,19-21,25-50,54}$ Since unfavourable histological features - such as high-grade dysplasia or $>20 \%$ villous component - predict a higher risk of metachronous advanced neoplasia, ${ }^{55}$ the identification of unfavourable histological features actually results into the assignment of a more intensive postpolypectomy surveillance (i.e., 3 -years vs. $-5 / 10$-years). ${ }^{5,6}$ Therefore, EC-based policies should be implemented only when the risk of advanced neoplasia may be marginalized. When comparing the prescreening prevalence of advanced neoplasia - ranging between $4 \%$ and $10 \%$ - with that of subcentimetric polyps, such prevalence would appear to be marginal - i.e., $\leq 1 \%$ - in diminutive lesions, whilst ranging between $1 \%$ and $5 \%$ in 6 to $9 \mathrm{~mm}$ lesions. ${ }^{7,856}$ Consequently, the actual drawback of a predict-resect-and-discard policy for diminutive lesions would be the lack of characterization of one case of advanced neoplasia every $\geq 100$ predictions, resulting into a 2/7-year delay in the postpolypectomy surveillance interval. Suggestively, the predict-resect-and-discard policy would still appear safer than the actual nonreferral policy implemented by computed tomography colonography and colon capsule, according to which diminutive lesions, irrespectively of whether (advanced) adenomatous or hyperplastic, should not even sent to post-test polypectomy. ${ }^{57,58}$ On the other hand, the application of EC-based policies to 6 to $9 \mathrm{~mm}$ lesions appears to be more controversial, because of the higher prevalence of advanced neoplasia within these lesions. ${ }^{7,46}$ However, the much lower prevalence of 6 to $9 \mathrm{~mm}$ as compared with $\leq 5$ $\mathrm{mm}$ lesions in the general population would marginalize the impact of these lesions over the efficiency of EC-policies. ${ }^{8}$ The second criticism to in vivo prediction of polyp histology is the 
possibility of EC-false-negatives/positives results when discriminating between hyperplastic and adenomatous polyps (Table 1). ${ }^{9,14-16,19-21,25-52}$ This would result in the risk of either anticipating the postpolypectomy surveillance interval in those with an hyperplastic lesion misclassified at EC as adenomatous or delaying it in those with an EC-misclassified adenomatous lesion. The clinical consequences of EC-misclassification would mainly depend on two variables, namely prevalence of adenomatous histotype and type of guidelines adopted. Similarly to advanced neoplasia prevalence, relative prevalence of adenomatous histotype within colorectal lesions is intimately related with polyp size, being about $50 \%$ and about $65 \%$ in diminutive and small lesions, respectively. ${ }^{7,59,60}$ Based on these values, when assuming a 90\% EC-based sensitivity for adenomatous histotype, the negative predictive value for adenomatous histology would equalize a $90 \%$ threshold for diminutive lesions, but it would be substantially inferior for 6 to $9 \mathrm{~mm}$ polyps. When limiting our analysis to diminutive lesions, polyp prevalence is also likely to be related with polyp location. Because of the well-known prevalence of several tiny hyperplastic lesions in the rectosigmoid tract, the relative prevalence of adenomatous histotype may be expected to be further reduced in this tract, as compared with the remaining colon. In a consecutive series of 235 distal polyps - including 220 $\leq 5 \mathrm{~mm}$ lesions - only 38 were actually adenomatous, corresponding to a $16 \%$ overall frequency of the adenomatous histotype. ${ }^{9}$ Because of the inverse relationship between adenomatous prevalence and negative predictive value, the very low disease prevalence in the rectosigmoid tract further reassure on the safety of EC-based policies in this location. The clinical impact of eventual false-positive/negative results at $\mathrm{EC}$ would also depend on the type of guidelines adopted. According to the United States and European-based guidelines, patients with one to two tubular subcentimetric adenomas should have their next surveillance examination at 5 to 10 years and 10 years, respectively. The impact of this 5 to 10 year difference on the implementation of EC-based policies is dramatic. If a 5-year interval is chosen, any false-positive/negative result at EC would cause an inappropriate anticipated/delayed surveillance interval for hyperplastic and adenomatous lesions, respectively, underlining the necessity for an optimal EC-accuracy in this scenario. On the other hand, if a 10 year interval for patients with one to two tubular subcentimetric adenomas is adopted, any false-positive/negative result would not affect the 10-year surveillance interval, since adenomatous and hyperplastic lesions would share a common 10-year interval recommendation in this scenario. The final criticism to ECbased policies is represented by the impossibility of differentiating between hyperplastic and nonhyperplastic serrated lesions - such as sessile serrated polyps or sessile serrated ade- nomas lesions - at EC, because of the similar EC characteristics of these lesions. ${ }^{14}$ However, prevalence of sessile or traditional serrated adenoma has been shown to be very low in subcentimetric lesions, being cumulatively present in $0.3 \%$ to $0.5 \%$ and $0.8 \%$ to $1.3 \%$ of diminutive and small lesions, respectively. ${ }^{7,60}$ Moreover, these lesions seem to be associated with a higher risk of synchronous or metachronous advanced neoplasia only when located in the proximal colon or larger than $10 \mathrm{~mm}^{.1}$

Based on all these considerations, the American Society for Gastrointestinal Endoscopy (ASGE) recently developed a preservation and incorporation of valuable endoscopic innovations (PIVI) statement for real-time endoscopic assessment of the histology of diminutive colorectal polyps ${ }^{62}$ In detail, it was determined that:

1) 'For colorectal polyps $<5 \mathrm{~mm}$ in size to be resected and discarded without pathologic assessment, endoscopic technology (when used with high confidence) used to determine histology of polyps $<5 \mathrm{~mm}$ in size, when combined with histopathologic assessment of polyps $>5 \mathrm{~mm}$ in size, should provide a $>90 \%$ agreement in assignment of postpolypectomy surveillance intervals when compared with decisions based on pathology assessment of all identified polyps.'

2) 'For a technology to be used to guide the decision to leave suspected rectosigmoid hyperplastic polyps $<5 \mathrm{~mm}$ in size in place (without resection), the technology should provide $>90 \%$ negative predictive value (when used with high confidence) for adenomatous histology?

The ASGE, therefore, recommended two different ECbased policies, namely a predict-resect-and-discard strategy for nonrectosigmoid $<5 \mathrm{~mm}$ lesions characterized at $\mathrm{EC}$ with high-confidence, and a predict-and-do-not-resect policy for rectosigmoid diminutive polyps predicted as hyperplastic at EC with high confidence. The overall algorithm is summarized in Fig. $1 .^{62}$

The ability of EC to meet with the $1^{\circ}$ PIVI has been tested in a few series (Table 2). ${ }^{9,15,16,19,25,46-50}$ When recommending a 5-year interval surveillance for low risk subcentimetric adenomas, ${ }^{5}$ the majority of the available series failed to match the $1^{\circ}$ PIVI, especially when EC was performed by less experienced endoscopists. On the other hand, when adopting a 10year schedule, most of the studies succeeded in meeting the $1^{\circ}$ PIVI. Intriguingly, when considering a 10 year interval for low-risk subcentimetric adenomas, a different strategy, in theory, would be to do-not-predict-resect-and-discard one to two diminutive lesions without EC-based prediction, reserving EC differentiation only to patients with at least three lesions. However, it is unclear whether the medical community would be ready to resect and discard lesions without having received any prediction about its histology. ${ }^{11}$ 
The $2^{\circ}$ PIVI is rather innovative, since it introduces the predict-and-do-not-resect strategy based on the main assumption that - after EC-prediction of hyperplastic histotype - the possibility of leaving in situ a $\leq 5 \mathrm{~mm}$ adenoma is too low to warrant the cost of polypectomy itself. Therefore, the predictand-do-not-resect policy represents a dramatic step forward in rationalizing the exploitation of medical and economic resources at colonoscopy, since it does not only exclude the pathological examination, but also the polypectomy itself from the colonoscopy procedure. When considering the low prevalence of adenomatous component among subcentimetric rectosigmoid lesions, it was not unexpected that the ma-

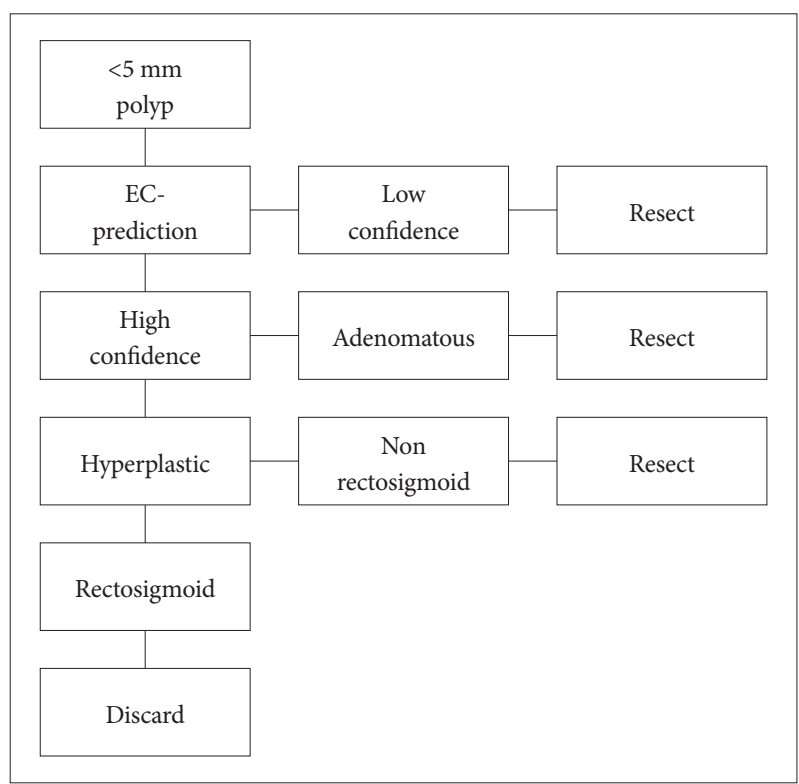

Fig. 1. Summary algorithm of the electronic chromoendoscopy (EC)-based proposed strategies according to American Society for Gastrointestinal Endoscopy recommendations. ${ }^{62}$ jority of the available studies consistently validated the feasibility of this policy, resulting into $>90 \%$ negative predictive values. The exclusion from this strategy of nonrectosigmoid lesions may be also expected to marginalize the risk of leaving high-risk serrated lesions in situ. However, it could also be argued that the drawback of this policy is to accept that 1 in every 10 patients with a rectosigmoid polyp discarded at EC would remain in situ, resulting into the risk of progression of one unresected diminutive EC-misclassified adenoma. At this regard, previous studies addressed the natural history of unresected diminutive or larger lesions in the recto-sigmoid tract, reassuring on the very low risk of progression of these lesions. In detail, Hoff et al. ${ }^{63}$ and Hofstad et al. ${ }^{64}$ followed up 194 diminutive and $253 \leq 10 \mathrm{~mm}$ polyps detected for 3 and 2 years, respectively. No diminutive polyp reached a $>5 \mathrm{~mm}$ size and only $0.5 \%$ of $\leq 10 \mathrm{~mm}$ polyps eclipsed the $10-\mathrm{mm}$ threshold after a 1-year time interval, and no case of severe dysplasia or carcinoma was registered. ${ }^{63,64}$ In a recent Japanese study only $2.9 \%$ of 408 subcentimetric lesions followed up for 43.1 months reached $\mathrm{a} \geq 10 \mathrm{~mm}$ size, without the occurrence of any invasive cancer. ${ }^{65}$ Overall these data may be reassuring, when considering the very low risk of discarding an (advanced) adenoma in the rectosigmoid colon.

\section{CONCLUSIONS}

The increasing volume of colonoscopy procedures - related with a growing awareness of the efficacy of CRC screening - in a period of economic constraint requires a rational exploitation of the limited medical and financial resources. This is further worsened by the additional volume of surveillance procedure generated by the detection of neoplastic lesions at the screening examination, especially when considering the

Table 2. Studies Reporting Accuracy of Electronic Chromoendoscopy in Matching the Desired Thresholds for the Two Porposed Preservation and Incorporation of Valuable Endoscopic innovations (see text)

\begin{tabular}{|c|c|c|c|c|c|c|}
\hline Author & Country & No. of points & No. of polyps & High/low confidence & $1^{\circ} \mathrm{PIVI}$ & $2^{\circ} \mathrm{PIVI}$ \\
\hline $\operatorname{Rex}^{16}$ & USA & 136 & 451 & Yes & Yes & - \\
\hline Ignjatovic et al. ${ }^{15}$ & UK & 130 & 278 & Yes & Yes & Yes \\
\hline Rastogi et al. ${ }^{45}$ & USA & - & - & No & No & No \\
\hline Gupta et al. ${ }^{46}$ & USA & 410 & 1,254 & No & No/Yes & Yes \\
\hline Hewett et al. ${ }^{47}$ & USA & 108 & 236 & Yes & - & Yes \\
\hline Kuiper et al. ${ }^{48}$ & The Netherlands & 308 & 108 & Yes & No & - \\
\hline Hewett et al. ${ }^{9}$ & US & 31 & 235 & Yes & - & Yes \\
\hline Paggi et al..$^{50}$ & Italy & 286 & 511 & Yes & No & - \\
\hline Longcroft-Wheaton et al. ${ }^{19}$ & UK & 51 & 150 & No & No/Yes & No \\
\hline Longcroft-Wheaton et al. ${ }^{19}$ & UK & 50 & 143 & No & Yes & No \\
\hline Ladabaum et al. ${ }^{49}$ & USA & 1,673 & 2,596 & Yes & No/Yes & Yes \\
\hline
\end{tabular}

PIVI, preservation and incorporation of valuable endoscopic innovation. 
increase in adenoma detection rate with the evolution of endoscopic technology and the development of quality assurance programs. For this reason, any policy that may simplify and rationalize colonoscopy procedure or work up is useful. Predict-resect-and-discard and predict-and-do-not-resect policies offer the advantage of saving the cost for polypectomy or postpolypectomy pathological examination in a substantial percentage of the cases, as well as to recommend on the same day of the colonoscopy procedure the recommended surveillance interval. In order to meet the desired clinical thresholds, however, EC-based policies require a careful reassessment of the current postpolypectomy surveillance guidelines. When considering the intrinsic limit of EC-accuracy, the recommendation of a 10-year interval for low-risk adenomas would minimize any risk of EC-based false-positive/negative result, prompting for an immediate implementation of these new policies in clinical practice.

\section{Conflicts of Interest}

The authors have no financial conflicts of interest.

\section{REFERENCES}

1. Winawer SJ, Zauber AG, Fletcher RH, et al. Guidelines for colonoscopy surveillance after polypectomy: a consensus update by the US MultiSociety Task Force on Colorectal Cancer and the American Cancer Society. CA Cancer J Clin 2006;56:143-159.

2. Kudo S, Lambert R, Allen JI, et al. Nonpolypoid neoplastic lesions of the colorectal mucosa. Gastrointest Endosc 2008;68(4 Suppl):S3-S47.

3. Rembacken B, Hassan C, Riemann JF, et al. Quality in screening colonoscopy: position statement of the European Society of Gastrointestinal Endoscopy (ESGE). Endoscopy 2012;44:957-968.

4. Rex DK, Alikhan M, Cummings O, Ulbright TM. Accuracy of pathologic interpretation of colorectal polyps by general pathologists in community practice. Gastrointest Endosc 1999;50:468-474.

5. Lieberman DA, Rex DK, Winawer SJ, et al. Guidelines for colonoscopy surveillance after screening and polypectomy: a consensus update by the US Multi-Society Task Force on Colorectal Cancer. Gastroenterology 2012;143:844-857.

6. Atkin WS, Valori R, Kuipers EJ, et al. European guidelines for quality assurance in colorectal cancer screening and diagnosis. First Edition: colonoscopic surveillance following adenoma removal. Endoscopy 2012;44 Suppl 3:SE151-SE163.

7. Gupta N, Bansal A, Rao D, et al. Prevalence of advanced histological features in diminutive and small colon polyps. Gastrointest Endosc 2012;75:1022-1030.

8. Hassan C, Pickhardt PJ, Kim DH, et al. Systematic review: distribution of advanced neoplasia according to polyp size at screening colonoscopy. Aliment Pharmacol Ther 2010;31:210-217.

9. Hewett DG, Huffman ME, Rex DK. Leaving distal colorectal hyperplastic polyps in place can be achieved with high accuracy by using narrow-band imaging: an observational study. Gastrointest Endosc 2012;76:374-380.

10. Hassan C, Pickhardt PJ, Rex DK. A resect and discard strategy would improve cost-effectiveness of colorectal cancer screening. Clin Gastroenterol Hepatol 2010;8:865-869.

11. Denis B, Bottlaender J, Weiss AM, et al. Some diminutive colorectal polyps can be removed and discarded without pathological examination. Endoscopy 2011;43:81-86.

12. Kessler WR, Imperiale TF, Klein RW, Wielage RC, Rex DK. A quantita- tive assessment of the risks and cost savings of forgoing histologic examination of diminutive polyps. Endoscopy 2011;43:683-691.

13. Joseph DA, King JB, Miller JW, Richardson LC; Centers for Disease Control and Prevention (CDC). Prevalence of colorectal cancer screening among adults: behavioral risk factor surveillance system, United States, 2010. MMWR Morb Mortal Wkly Rep 2012;61 Suppl:51-56.

14. Rastogi A, Bansal A, Wani S, et al. Narrow-band imaging colonoscopy: a pilot feasibility study for the detection of polyps and correlation of surface patterns with polyp histologic diagnosis. Gastrointest Endosc 2008;67:280-286.

15. Ignjatovic A, East JE, Suzuki N, Vance M, Guenther T, Saunders BP. Optical diagnosis of small colorectal polyps at routine colonoscopy (Detect InSpect ChAracterise Resect and Discard; DISCARD trial): a prospective cohort study. Lancet Oncol 2009;10:1171-1178.

16. Rex DK. Narrow-band imaging without optical magnification for histologic analysis of colorectal polyps. Gastroenterology 2009;136:11741181.

17. Kato S, Fujii T, Koba I, et al. Assessment of colorectal lesions using magnifying colonoscopy and mucosal dye spraying: can significant lesions be distinguished? Endoscopy 2001;33:306-310.

18. Kudo S, Tamura S, Nakajima T, Yamano H, Kusaka H, Watanabe H. Diagnosis of colorectal tumorous lesions by magnifying endoscopy. Gastrointest Endosc 1996;44:8-14.

19. Longcroft-Wheaton G, Brown J, Cowlishaw D, Higgins B, Bhandari P. High-definition vs. standard-definition colonoscopy in the characterization of small colonic polyps: results from a randomized trial. Endoscopy 2012;44:905-910.

20. Chiu HM, Chang CY, Chen CC, et al. A prospective comparative study of narrow-band imaging, chromoendoscopy, and conventional colonoscopy in the diagnosis of colorectal neoplasia. Gut 2007;56:373-379.

21. Su MY, Hsu CM, Ho YP, Chen PC, Lin CJ, Chiu CT. Comparative study of conventional colonoscopy, chromoendoscopy, and narrowband imaging systems in differential diagnosis of neoplastic and nonneoplastic colonic polyps. Am J Gastroenterol 2006;101:2711-2716.

22. Lambert R, Provenzale D, Ectors N, et al. Early diagnosis and prevention of sporadic colorectal cancer. Endoscopy 2001;33:1042-1064.

23. Lambert R, Kudo SE, Vieth M, et al. Pragmatic classification of superficial neoplastic colorectal lesions. Gastrointest Endosc 2009;70:11821199.

24. Hassan C, Zullo A, Cristofari F, Lorenzetti R. Upper endoscopy in Europe: are we missing gastric cancer? J Clin Gastroenterol 2010;44:73.

25. Machida H, Sano Y, Hamamoto Y, et al. Narrow-band imaging in the diagnosis of colorectal mucosal lesions: a pilot study. Endoscopy 2004; 36:1094-1098.

26. East JE, Suzuki N, Saunders BP. Comparison of magnified pit pattern interpretation with narrow band imaging versus chromoendoscopy for diminutive colonic polyps: a pilot study. Gastrointest Endosc 2007;66: 310-316.

27. Tischendorf JJ, Wasmuth HE, Koch A, Hecker H, Trautwein C, Winograd R. Value of magnifying chromoendoscopy and narrow band imaging (NBI) in classifying colorectal polyps: a prospective controlled study. Endoscopy 2007;39:1092-1096.

28. East JE, Suzuki N, Bassett P, et al. Narrow band imaging with magnification for the characterization of small and diminutive colonic polyps: pit pattern and vascular pattern intensity. Endoscopy 2008;40:811-817.

29. Sano Y, Ikematsu H, Fu KI, et al. Meshed capillary vessels by use of narrow-band imaging for differential diagnosis of small colorectal polyps. Gastrointest Endosc 2009;69:278-283.

30. van den Broek FJ, van Soest EJ, Naber AH, et al. Combining autofluorescence imaging and narrow-band imaging for the differentiation of adenomas from non-neoplastic colonic polyps among experienced and non-experienced endoscopists. Am J Gastroenterol 2009;104:1498-1507.

31. Wada Y, Kudo SE, Kashida H, et al. Diagnosis of colorectal lesions with the magnifying narrow-band imaging system. Gastrointest Endosc 2009; 70:522-531 
32. Tischendorf JJ, Gross S, Winograd R, et al. Computer-aided classification of colorectal polyps based on vascular patterns: a pilot study. Endoscopy 2010;42:203-207.

33. Tischendorf JJ, Schirin-Sokhan R, Streetz K, et al. Value of magnifying endoscopy in classifying colorectal polyps based on vascular pattern. Endoscopy 2010;42:22-27.

34. Gross S, Trautwein C, Behrens A, et al. Computer-based classification of small colorectal polyps by using narrow-band imaging with optical magnification. Gastrointest Endosc 2011;74:1354-1359.

35. Ignjatovic A, East JE, Guenther T, et al. What is the most reliable imaging modality for small colonic polyp characterization? Study of whitelight, autofluorescence, and narrow-band imaging. Endoscopy 2011;43: 94-99.

36. Sato R, Fujiya M, Watari J, et al. The diagnostic accuracy of high-resolution endoscopy, autofluorescence imaging and narrow-band imaging for differentially diagnosing colon adenoma. Endoscopy 2011;43:862868.

37. Yoo HY, Lee MS, Ko BM, et al. Correlation of narrow band imaging with magnifying colonoscopy and histology in colorectal tumors. Clin Endosc 2011;44:44-50.

38. Kuiper T, van den Broek FJ, van Eeden S, Fockens P, Dekker E. Feasibility and accuracy of confocal endomicroscopy in comparison with narrow-band imaging and chromoendoscopy for the differentiation of colorectal lesions. Am J Gastroenterol 2012;107:543-550.

39. Takemura Y, Yoshida S, Tanaka S, et al. Computer-aided system for predicting the histology of colorectal tumors by using narrow-band imaging magnifying colonoscopy (with video). Gastrointest Endosc 2012;75: 179-185.

40. Rogart JN, Jain D, Siddiqui UD, et al. Narrow-band imaging without high magnification to differentiate polyps during real-time colonoscopy: improvement with experience. Gastrointest Endosc 2008;68:11361145.

41. Sikka S, Ringold DA, Jonnalagadda S, Banerjee B. Comparison of white light and narrow band high definition images in predicting colon polyp histology, using standard colonoscopes without optical magnification. Endoscopy 2008;40:818-822.

42. Buchner AM, Shahid MW, Heckman MG, et al. Comparison of probebased confocal laser endomicroscopy with virtual chromoendoscopy for classification of colon polyps. Gastroenterology 2010;138:834-842.

43. Henry ZH, Yeaton P, Shami VM, et al. Meshed capillary vessels found on narrow-band imaging without optical magnification effectively identifies colorectal neoplasia: a North American validation of the Japanese experience. Gastrointest Endosc 2010;72:118-126.

44. Ignjatovic A, Thomas-Gibson S, East JE, et al. Development and validation of a training module on the use of narrow-band imaging in differentiation of small adenomas from hyperplastic colorectal polyps. Gastrointest Endosc 2011;73:128-133.

45. Rastogi A, Early DS, Gupta N, et al. Randomized, controlled trial of standard-definition white-light, high-definition white-light, and narrow-band imaging colonoscopy for the detection of colon polyps and prediction of polyp histology. Gastrointest Endosc 2011;74:593-602.

46. Gupta N, Bansal A, Rao D, et al. Accuracy of in vivo optical diagnosis of colon polyp histology by narrow-band imaging in predicting colonoscopy surveillance intervals. Gastrointest Endosc 2012;75:494-502.

47. Hewett DG, Kaltenbach T, Sano Y, et al. Validation of a simple classification system for endoscopic diagnosis of small colorectal polyps using narrow-band imaging. Gastroenterology 2012;143:599-607.

48. Kuiper T, Marsman WA, Jansen JM, et al. Accuracy for optical diagnosis of small colorectal polyps in nonacademic settings. Clin Gastroenterol Hepatol 2012;10:1016-1020.

49. Ladabaum U, Fioritto A, Mitani A, et al. Real-time optical biopsy of colon polyps with narrow band imaging in community practice does not yet meet key thresholds for clinical decisions. Gastroenterology 2013; 144:81-91.

50. Paggi S, Rondonotti E, Amato A, et al. Resect and discard strategy in clinical practice: a prospective cohort study. Endoscopy 2012;44:899-904.

51. Hirata M, Tanaka S, Oka S, et al. Magnifying endoscopy with narrow band imaging for diagnosis of colorectal tumors. Gastrointest Endosc 2007;65:988-995.

52. Kuiper T, van den Broek FJ, Naber AH, et al. Endoscopic trimodal imaging detects colonic neoplasia as well as standard video endoscopy. Gastroenterology 2011;140:1887-1894.

53. Raghavendra M, Hewett DG, Rex DK. Differentiating adenomas from hyperplastic colorectal polyps: narrow-band imaging can be learned in 20 minutes. Gastrointest Endosc 2010;72:572-576.

54. Pohl J, Nguyen-Tat M, Pech O, May A, Rabenstein T, Ell C. Computed virtual chromoendoscopy for classification of small colorectal lesions: a prospective comparative study. Am J Gastroenterol 2008;103:562-569.

55. Martinez ME, Baron JA, Lieberman DA, et al. A pooled analysis of advanced colorectal neoplasia diagnoses after colonoscopic polypectomy. Gastroenterology 2009;136:832-841.

56. Pickhardt PJ, Hain KS, Kim DH, Hassan C. Low rates of cancer or high-grade dysplasia in colorectal polyps collected from computed tomography colonography screening. Clin Gastroenterol Hepatol 2010;8: 610-615.

57. Zalis ME, Barish MA, Choi JR, et al. CT colonography reporting and data system: a consensus proposal. Radiology 2005;236:3-9.

58. Spada C, Hassan C, Galmiche JP, et al. Colon capsule endoscopy: European Society of Gastrointestinal Endoscopy (ESGE) Guideline. Endoscopy 2012;44:527-536.

59. Pickhardt PJ, Choi JR, Hwang I, et al. Computed tomographic virtual colonoscopy to screen for colorectal neoplasia in asymptomatic adults. N Engl J Med 2003;349:2191-2200.

60. Lieberman D, Moravec M, Holub J, Michaels L, Eisen G. Polyp size and advanced histology in patients undergoing colonoscopy screening: implications for CT colonography. Gastroenterology 2008;135:1100-1105.

61. Schreiner MA, Weiss DG, Lieberman DA. Proximal and large hyperplastic and nondysplastic serrated polyps detected by colonoscopy are associated with neoplasia. Gastroenterology 2010;139:1497-1502.

62. Rex DK, Kahi C, O'Brien M, et al. The American Society for Gastrointestinal Endoscopy PIVI (Preservation and Incorporation of Valuable Endoscopic Innovations) on real-time endoscopic assessment of the histology of diminutive colorectal polyps. Gastrointest Endosc 2011;73: 419-422.

63. Hoff G, Foerster A, Vatn MH, Sauar J, Larsen S. Epidemiology of polyps in the rectum and colon. Recovery and evaluation of unresected polyps 2 years after detection. Scand J Gastroenterol 1986;21:853-862.

64. Hofstad B, Vatn MH, Andersen SN, et al. Growth of colorectal polyps: redetection and evaluation of unresected polyps for a period of three years. Gut 1996;39:449-456.

65. Hisabe T, Tsuda S, Matsui T, Iwashita A. Natural history of small colorectal protuberant adenomas. Dig Endosc 2010;22 Suppl 1:S43-S46. 